\title{
Ewings Sarcoma-Primitive Neuroectodermal Tumour-Rare Extraosseous Presentation
}

\author{
Arcot Rekha*, Prabhu Purushothaman, Rufus Ranjitsingh Edwin, Anukiran Ravichandran \\ Sri Ramachandra Medical College and Research Institute, Chennai, India \\ Email: rrekha_a@yahoo.com
}

Received 21 December 2015; accepted 14 March 2016; published 17 March 2016

Copyright @ 2016 by authors and Scientific Research Publishing Inc.

This work is licensed under the Creative Commons Attribution International License (CC BY). http://creativecommons.org/licenses/by/4.0/

(c) (i) Open Access

\begin{abstract}
Introduction: Ewings sarcoma is uncommon in extra osseous locations. They belong to Ewings family of tumours and the primitive neuroectodermal tumour is often diagnosed based on immuno histochemistry and molecular genetic studies. Discussion: A 50-year-old gentleman presented with complaints of a swelling in the right thigh. With a diagnosis of soft tissue sarcoma, the patient underwent a wide local excision of the tumour. We review literature of the small round blue cell tumour. Conclusion: Extraosseous Ewings sarcoma presenting as a thigh swelling is uncommon. The sarcoma was vimentin positive and CD99 membrane positivity.
\end{abstract}

\section{Keywords}

Ewings Sarcoma, Extra Osseous, Primitive Neuroectodermal Tumour

\section{Introduction}

Ewings sarcoma (ES) family of tumours include classic Ewings sarcoma of the bone, small cell tumour of the thorax and primitive neuroectodermal tumour (PNET) of the soft tissue. They are often referred to as the small round cell tumours.

\section{Case Report}

A 50-year-old gentleman presented with complaints of a swelling in the upper thigh of six months duration. The swelling had slowly increased in size and was occasionally associated with discomfort. There were no pressure symptoms and no constitutional symptoms. Examination revealed a $9 \times 9 \mathrm{cms}$ smooth well defined swelling, occupying the anterior and medial aspect of the right upper thigh (Figure 1). There were no scars or distended

${ }^{*}$ Corresponding author.

How to cite this paper: Rekha, A., Purushothaman, P., Edwin, R.R. and Ravichandran, A. (2016) Ewings Sarcoma-Primitive Neuroectodermal Tumour-Rare Extraosseous Presentation. Case Reports in Clinical Medicine, 5, 95-100. 


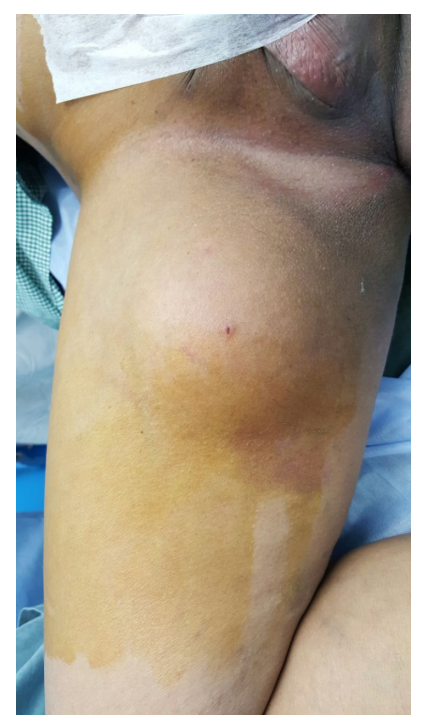

Figure 1. Showing the tumour in the thigh.

veins and there was no distal neurovascular deficit. MRI report showed T2W hyperintense mass visualized in medial compartment of the right upper thigh, within the superficial part of adductor longus muscle. Few minimally haemorrhagic areas were visualised within the mass and the mass was postero medial to the femoral vessels (Figure 2).

With a working diagnosis of a soft tissue sarcoma, the patients underwent a Tru cut biopsy of the lesion which showed a neoplasm composed of cells arranged in sheaths. The individual cells were round to polygonal with increased nuclear cytoplasmic ratio and scant cytoplasm. Focal areas showed cells arranged in perivascular pattern and occasional mitotic figures. The impression was that of small round blue cell tumour. Chest X Ray and metastatic work up were negative.

The patient underwent a wide local excision of the tumour where it was found to be involving the anterior and the medial compartment, adherent to the adductor longus, brevis and partly to the adductor magnus. Laterally the lesion was found abutting the femoral sheath .Wide local excision of the tumour was done preserving the femoral vein (Figure 3). Postoperative period was relatively uneventful and the patient was referred to the oncologist for radiotherapy and chemotherapy. The final histology showed primitive neurectodermal/Ewings sarcoma with margins free of tumour. The tumour was vimentin positive, CD45 negative SMA negative and CD99 showing membrane positivity in tumour cells (Figure 4).

\section{Discussion}

Ewings sarcoma family of tumours are tumours of small round cells that are morphologically similar [1] [2]. Ewings sarcoma (ES) includes Ewings of the bone [3]-[6], extraosseous Askins tumour and the primitive neuroectodermal soft tissue tumour (PNET). The term PNET first described by Hart and Earle denotes small round cell tumours with varying degrees of neural, glial and ependymal differentiation [7] [8]. ES and PNET are two extremes of a morphological spectrum. They have similar immunohistochemical, cytogenetic and clinical profiles.

The diagnosis is based on light microscopy, immuohistochemistry, electron microscopy and molecular genetic studies [8]-[10]. Light microscopy shows primitive small round cells with increased nuclear cytoplasmic ratios. PNET are positive for CD 99(a $32 \mathrm{KDa}$ cell surface glycoprotein coded by MIC 2 gene).This is also seen in lymphoblastic lymphoma. Electron microscopy shows aggregated glycogen granules in the cytoplasm. Microtubules and neurosecretory granules may be seen in the cells with neural differentiation [8]. Chromosomal translocation such as $\mathrm{t}(11 ; 22)$ (q24;q12) seen in $88 \%$ - 95\% of ES/PNET can be detected by RT PCR or by FISH in molecular genetic studies. In $90 \%$ - 95\% of cases of ES/PNET, the chimeric transcript an aberrant fusion protein EWS-FLI-1 is detected in molecular biologic examination.

The treatment of soft tissue sarcoma is based on the stage and grade of the tumour. When the lesion is greater 


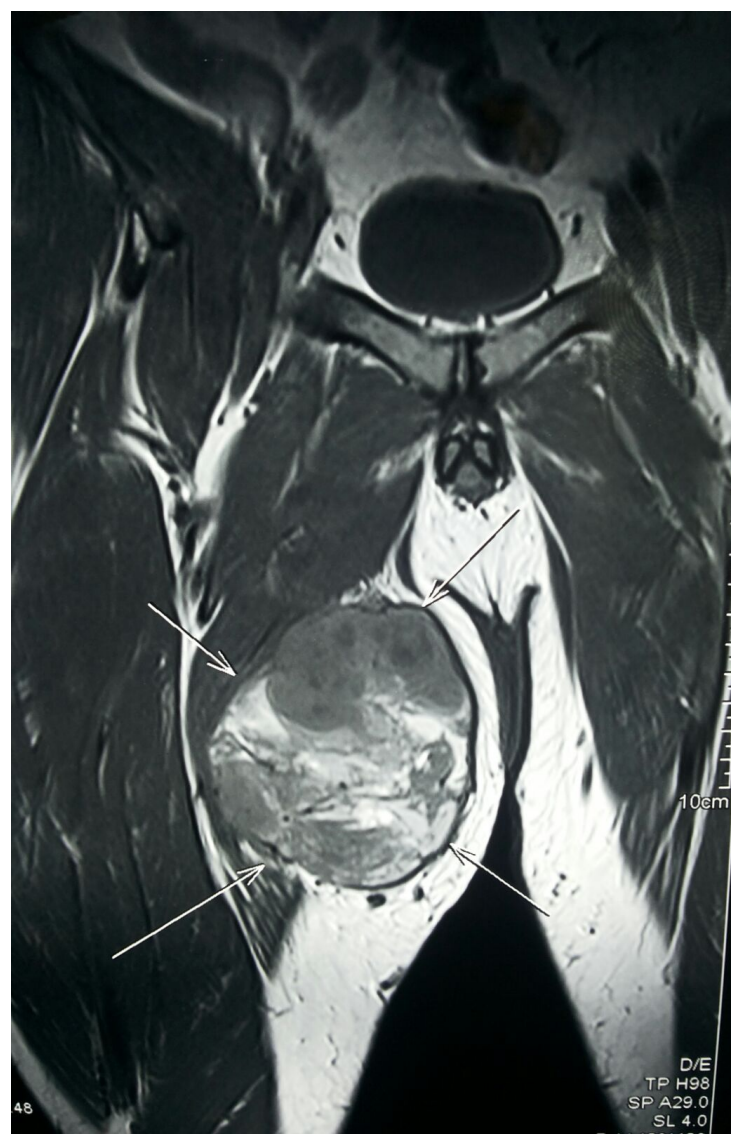

Figure 2. MRI of the sarcoma.
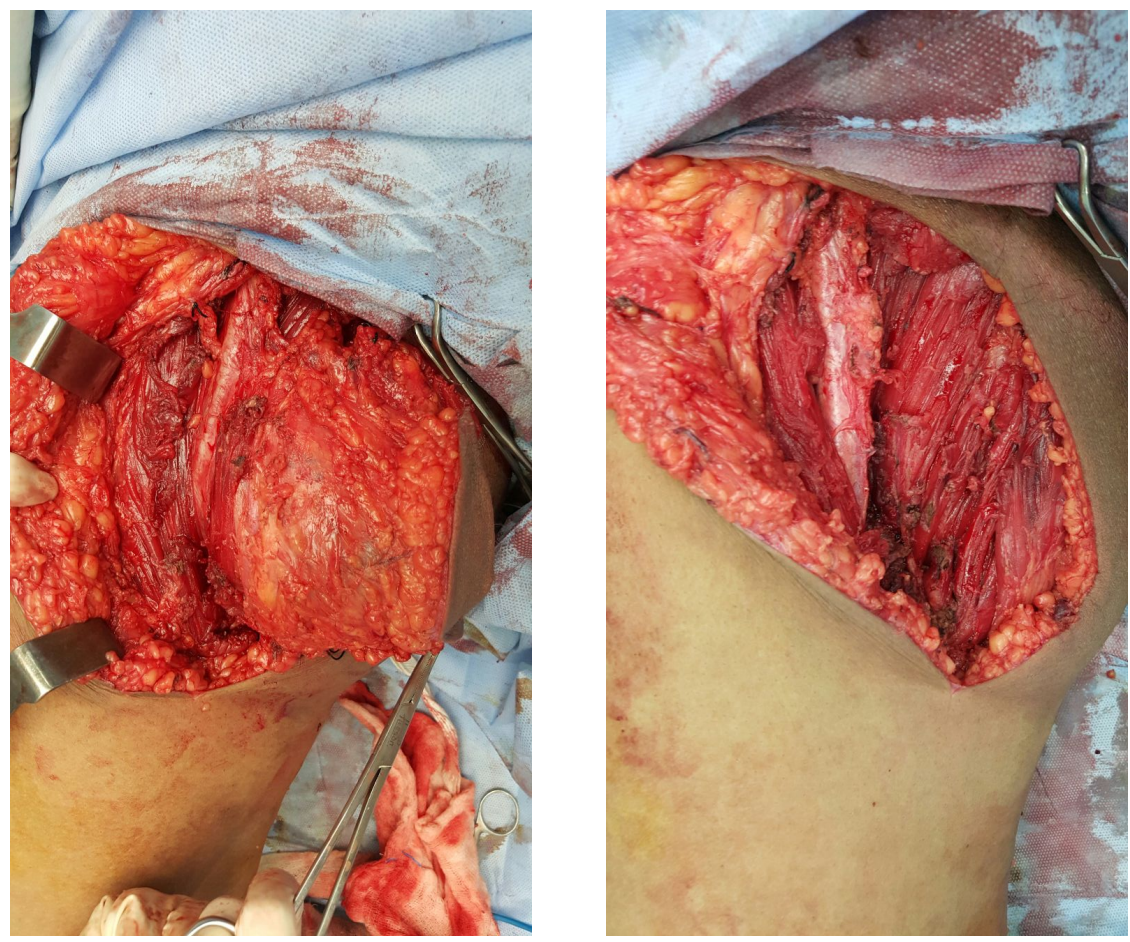

Figure 3. Showing the tumour excision. 


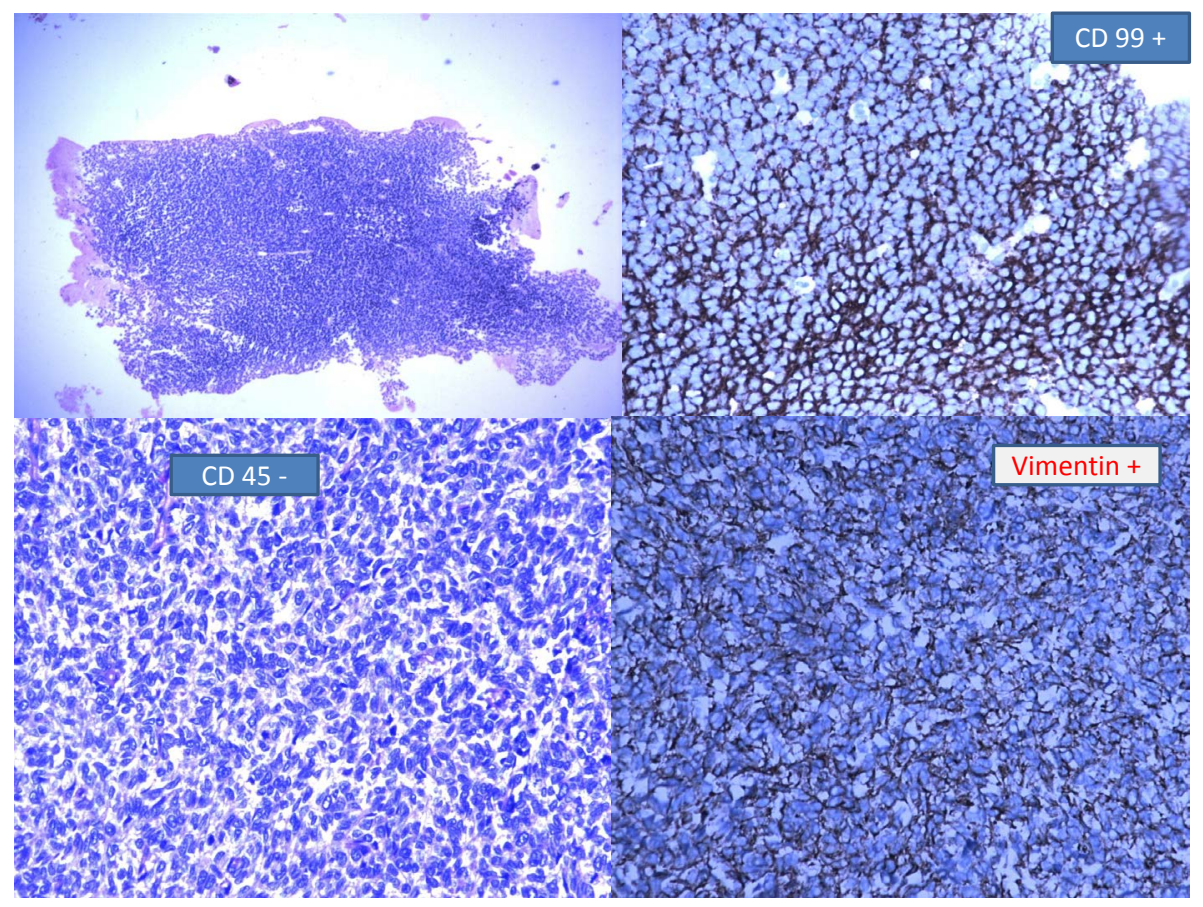

Figure 4. Shows the small round blue cell tumour and the immunohistochemistry.

than $1 \mathrm{~cm}$ margin and the fascia is intact, the treatment is wide local excision. $\mathrm{E}$ When the margin is less than adjuvant radiotherapy reduces the risk of local recurrence thgough it does not improve survival. Definitive radiotherapy is considered when the candidates are not fit for surgery. High grade tumours require adjuvant radiotherapy and/or chemotherapy. Post radiotherapy re resection may be considered in large and high grade tumours. Metastatic disease is treated with palliative radiotherapy or chemotherapy and the results are poor.

The gold standard in management is surgical excision with negative margins [11] [12]. Chemotherapy improves survival and reduces the incidence of local recurrence. Chemotherapy regimens include vincristine, cyclophosphamide actinomycin D and doxorubicin. Other drugs include ifosfamide, etoposide. Radiotherapy can be used to achieve longer disease free survival and to prevent local recurrence.

\section{Recent Advances}

Newer modalities of therapy include targeted therapy aimed at the insulin like growth factor receptor (IGF -1R), which is believed to play a role in the pathogenesis of ES. Antibodies directed against the IGF-1 receptor protein have also been studied as a potential treatment for advanced ESFT [13] [14]. A phase 1 clinical trial of Figitumumab, an IGF-R1 antibody, was recently reported. Two of 16 ESFT patients responded to treatment and eight had disease stabilization for four months or longer. This agent and other similar antibodies are undergoing further study.

By studying the molecular pathway of ESFT and the EWS-FLI fusion protein, investigators discovered that repetitive sequences of DNA called microsatellites function as response elements in the ESFT pathway [15]. Subsequently, they were able to identify a protein called GSTM4 which is found in high levels among patients who do not respond to chemotherapy (Luo, 2009). This discovery may permit the early identification of patients who will not respond as well to standard treatment. Agents that interfere with GSTM4 may ultimately be developed to treat ESFT. Investigation of the fusion protein biological pathway has also identified a protein called NR0B1 as an important component of the pathway which may also ultimately be targeted for therapy.

Research showed that EWS-FLI binds a molecule called RNA Helicase A which functions in the regulation of genetic transcription .Recently, they identified a small molecule, YK-4-279, which interferes with the binding of EWS-FLI to RNA Helicase A. This molecule killed ESFT cells in culture and decreased ESFT tumor growth in an animal model.

CD99 is another molecule being studied as a potential immunotherapy target for the treatment of ESFT. CD99 
is present on most ESFT tumor cells. Recent research suggests that it plays a role in preventing the normal neural differentiation of Ewing cells (Rocchi, 2010). Human trials targeting CD99 are Tumor cell suicide via programmed cell death or apoptosis may be facilitated by a molecule entitled tumor necrosis factor-related apoptosis inducing ligand (TRAIL). This molecule was shown to kill Ewing's cells in vitro and may prove to be a useful biologic therapy (Mitsiades, 2001 and Van Valen, 2000). A pre-clinical study showing efficacy of TRAIL in animals was recently reported (Picarda, 2010). These and other drugs are purely investigational at this point [16] [17].

\section{Conclusion}

The PNET variant of Ewings sarcoma occurs but rarely. The readers may refer to standard books for management protocols of soft tissue sarcomas. This is presented to discuss the small uncommon variant of small round blue cell tumours on the core biopsy. Surgical wide excision is the mainstay in treatment while immunohistochemistry is the key in the diagnosis of the rare extraosseous PNET Ewings sarcoma.

\section{References}

[1] Renard, C. and Ranchère-Vince, D. (2015) Ewing/PNET Sarcoma Family of Tumors: Towards a New Paradigm? Annales de Pathologie, 35, 86-97. http://dx.doi.org/10.1016/j.annpat.2014.11.001

[2] Tao, H.T., Hu, Y., Wang, J.L., Cheng, Y., Zhang, X., Wang, H. and Zhang, S.J. (2013) Extraskeletal Ewing Sarcomas in Late Adolescence and Adults: A Study of 37 Patients. Asian Pacific Journal of Cancer Prevention, 14, $2967-2971$. http://dx.doi.org/10.7314/APJCP.2013.14.5.2967

[3] Hanson, B., Ubert, A., Dyer, B. and Richmond, B. (2013) Adult Soft Tissue Ewing's Sarcoma/Primitive Neuroectodermal Tumor. Annals of Surgery, 79, E249-E250.

[4] Liu, Z., Wang, X., Lu, Y., Chen, L. and Lu, Y. (2014) Primary Ewing Sarcoma/Primitive Neuroectodermal Tumor of the Renal Pelvis: A Case Report. World Journal of Surgical Oncology, 12, 293. http://dx.doi.org/10.1186/1477-7819-12-293

[5] Huh, J., Kim, K.W., Park, S.J., Kim, H.J., Lee, J.S., Ha, H.K., Tirumani, S.H. and Ramaiya, N.H. (2015) Imaging Features of Primary Tumors and Metastatic Patterns of the Extraskeletal Ewing Sarcoma Family of Tumors in Adults: A 17-Year Experience at a Single Institution. Korean Journal of Radiology, 16, 783-790. http://dx.doi.org/10.3348/kjr.2015.16.4.783

[6] Gomaa, W.M. and Al-Maghrabi, J.A. (2012) Ewing's Sarcoma Family Tumors in the Western Region of Saudi Arabia. A Pathological Experience from 2 Tertiary Medical Centers. Saudi Medical Journal, 33, 418-422.

[7] Hart, M.N. and Earle, K.M. (1973) Primitive Neuroectodermal Tumors of the Brain in Children. Cancer, 32, $890-897$. http://dx.doi.org/10.1002/1097-0142(197310)32:4<890::AID-CNCR2820320421>3.0.CO;2-O

[8] Wei, S. and Siegal, G.P. (2014) Round Cell Tumors of Bone: An Update on Recent Molecular Genetic Advances. Advances in Anatomic Pathology, 21, 359-372. http://dx.doi.org/10.1097/PAP.0000000000000036

[9] Li, Q., Cui, W., Abulajiang, G., Ma, Y., Liu, X., Zhang, W. and Li, X. (2014) Application of Immunohistochemistry in the Diagnosis of Small Round Blue-Cell Tumors of Soft Tissue. Clinical Laboratory, 60, 1383-1392.

[10] Papotti, M., Abbona, G., Pagani, A., Monga, G. and Bussolati, G. (1998) Primitive Neuroectodermal Tumor of the Meninges: An Histologic, Immunohistochemical, Ultrastructural and Cytogenetic Study. Endocrine Pathology, 3, 275280. http://dx.doi.org/10.1007/BF02739968

[11] Mardekian, S.K., Gandhe, A., Miettinen, M., Pack, S., Curtis, M.T. and Abdullaev, Z. (2014) Two Cases of Spinal, Extraosseous, Intradural Ewing’s Sarcoma/Peripheral Neuroectodermal Tumor: Radiologic, Pathologic, and Molecular Analysis. Journal of Clinical Imaging Science, 4, 6. http://dx.doi.org/10.4103/2156-7514.126050

[12] Biswas, B., Shukla, N.K., Deo, S.V., Agarwala, S., Sharma, D.N., Vishnubhatla, S. and Bakhshi, S. (2014) Evaluation of Outcome and Prognostic Factors in Extraosseous Ewing Sarcoma. Pediatric Blood \& Cancer, 61, 1925-1931. http://dx.doi.org/10.1002/pbc.25095

[13] Kelleher, F.C. and Thomas, D.M. (2012) Molecular Pathogenesis and Targeted Therapeutics in Ewing Sarcoma/Primitive Neuroectodermal Tumours. Clinical Sarcoma Research, 2, 6. http://dx.doi.org/10.1186/2045-3329-2-6

[14] Fernandez-Flores, A., Suarez-Peñaranda, J.M. and Alonso, S. (2013) Study of EWS/FLI-1 Rearrangement in 18 Cases of CK20+/CM2B4+ Merkel Cell Carcinoma Using FISH and Correlation to the Differential Diagnosis of Ewing Sarcoma/Peripheral Neuroectodermal Tumor. Applied Immunohistochemistry \& Molecular Morphology, 21, 379-385. http://dx.doi.org/10.1097/PAI.0b013e318273a9e0

[15] Le Deley, M.C., Delattre, O., Schaefer, K.L., Burchill, S.A., Koehler, G., Hogendoorn, P.C., Lion, T., Poremba, C., 
Marandet, J., Ballet, S., Pierron, G., Brownhill, S.C., Nesslböck, M., Ranft, A., Dirksen, U., Oberlin, O., Lewis, I.J., Craft, A.W., Jürgens, H. and Kovar, H. (2010) Impact of EWS-ETS Fusion Type on Disease Progression in Ewing's Sarcoma/Peripheral Primitive Neuroectodermal Tumor: Prospective Results from the Cooperative Euro-E.W.I.N.G. 99 Trial. Journal of Clinical Oncology, 28, 1982-1988. http://dx.doi.org/10.1200/JCO.2009.23.3585

[16] Marec-Bérard, P., Chotel, F. and Claude, L. (2010) PNET/Ewing Tumours: Current Treatments and Future Perspectives. Bulletin du Cancer, 97, 707-713.

[17] Kelleher, F.C. and Thomas, D.M. (2012) Molecular Pathogenesis and Targeted Therapeutics in Ewing Sarcoma/Primitive Neuroectodermal Tumours. Clinical Sarcoma Research, 2, 6. http://dx.doi.org/10.1186/2045-3329-2-6 